\title{
Rheumatoid lung cavitation and response to penicillamine
}

\section{J SPENCER JONES}

\author{
From the Royal Victoria Hospital, Folkestone
}

Lung cavitation is an uncommon manifestation of rheumatoid disease. It may arouse suspicion of tuberculosis, cavitated carcinoma, or the lung abscess that it may later become if infected. Early recognition is desirable because there are three reports of permanent cavity closure in response to treatment-by gold,' prednisone, ${ }^{2}$ and azathioprine. ${ }^{3}$ These relate to the type of cavity described by Dumas et al, ${ }^{4}$ not the type associated with upper lobe fibrosis. $^{5}$

\section{Case report}

A business man aged 54 years had a small haemoptysis in 1981 and the chest radiograph showed a few poorly defined nodules at the apex of the right lung. Twelve months later he had severe joint pains on extremes of movement in the small hand joints, shoulders, and knees. He took piroxicam $50 \mathrm{mg}$ twice daily with indomethacin $50 \mathrm{mg}$ at night with benefit and four months later, after physiotherapy, there was no objective evidence of rheumatoid arthritis, though the joints still ached. The erythrocyte sedimentation rate (ESR) was $16 \mathrm{~mm}$ in one hour, with a normal $\mathrm{C}$ reactive protein concentration. The level of rheumatoid factor in the blood was $15 \mathrm{IU} / \mathrm{ml}$ (normal < 15).

In September 1985 he had some small haemoptyses with malaise and sweating and tuberculosis was suspected by the radiologist (fig 1). On auscultation no pretussive or post-

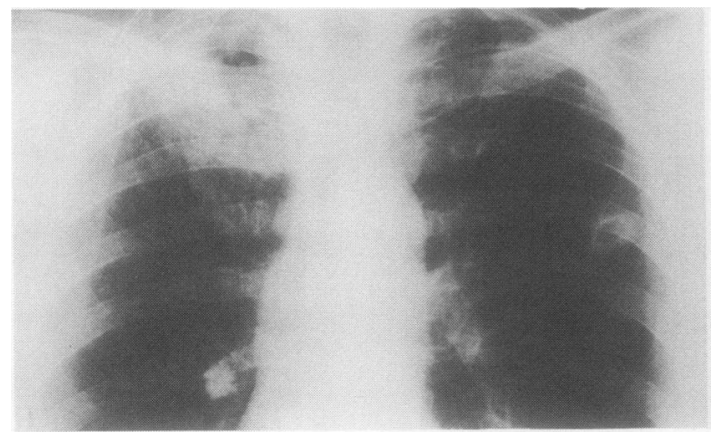

Fig 1 Chest radiograph taken after haemoptysis with malaise, showing rheumatoid cavitation in left upper lobe and consolidation in right upper lobe.

Address for reprint requests: Dr J Spencer Jones, 8 Lower Blackhouse Hill, Hythe, Kent CT21 5LS.

Accepted 3 May 1987

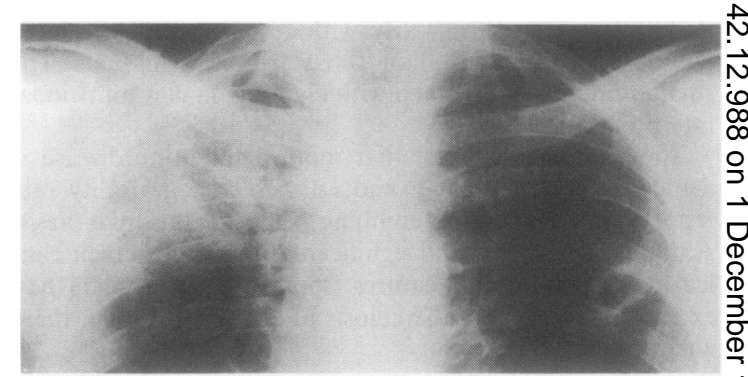

Fig 2 Development of rheumatoid cavity in right upper lobe four weeks later.

tussive crepitations were audible. He was now so ill that sevene weeks of isoniazid $0.3 \mathrm{~g}$, rifampicin $0.6 \mathrm{~g}$, and ethambutol 1.05 $\mathrm{g}$ daily were given after sputum specimens had been collected $\overline{\mathrm{O}}$ these showed mixed organisms and no acid fast bacilli. Aftein one week's treatment he was more toxic, with a pulse rate of 108 beats $/ \mathrm{min}$. A fresh $4.2 \times 2.3 \mathrm{~cm}$ diameter cavity had appeared in the upper lobe of the right lung (fig 2). The cavity in the upper lobe of the left lung enlarged from 1.3 to $3.4 \mathrm{~cm}$ in diameter despite the addition of daily amoxycillin $750 \mathrm{mg}$ for five days, and four acute phase reactants were found to be abnormal with a $C$ reactive protein level of $0.1 \mathrm{~g} /$ litre (norma $<0.01 \mathrm{~g} /$ litre). Rheumatoid cavitation was diagnosed, buti treatment was not stopped until after six weeks a culture negative for Mycobacterium tuberculosis had been obtained.

Penicillamine $1.0 \mathrm{~g}$ daily was then administered in hospital after smaller doses had been given for 11 days; it waso combined with naproxen $50 \mathrm{mg}$ twice daily and temazepam $10 \mathrm{mg}$ at night. He received no other treatment, then oro subsequently. The cavity in the left lung was at its maximum diameter of $7.7 \mathrm{~cm}$ (fig 3) at the time penicillamine waso

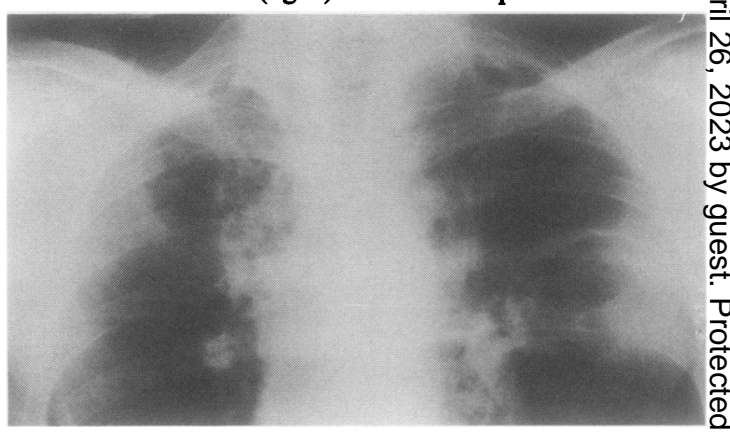

Fig 3 Bilateral rheumatoid cavitation at the start of penicillamine treatment (seven weeks after fig 2). 


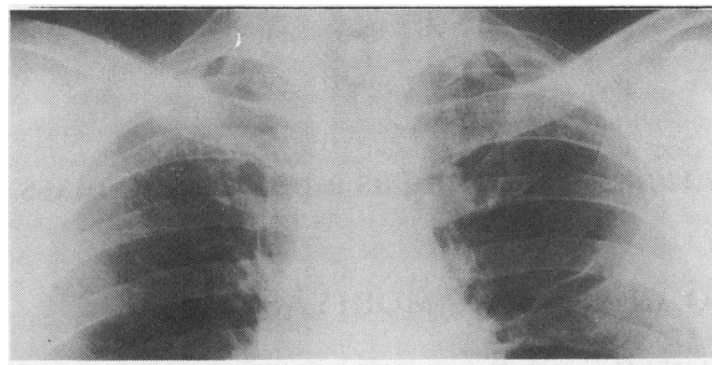

Fig 4 Resolution of lung disease and cavity closure after six months of treatment with penicillamine $1.0 \mathrm{~g}$ daily.

started. Dramatic improvement now occurred and sweating and blood staining of sputum both ceased. His weight had increased from 73 to $77 \mathrm{~kg}$ by the time he was discharged from hospital six weeks later, and it rose to $83 \mathrm{~kg}$ thereafter. Two months after starting penicillamine he had resumed work for eight instead of the previous 10 hours daily. The maximum thickness of the cavity walls was now $0.1 \mathrm{~cm}$, compared with $0.5 \mathrm{~cm}$ previously, and the ESR was $15 \mathrm{~mm}$ in one hour, with normal acute phase reactants.

Bilateral cavity closure occurred five months after he started penicillamine (fig 4) and was tomographically confirmed at 13 months, four months after the penicillamine dosage had been stabilised at $0.5 \mathrm{~g}$ daily. A dose reduction to $375 \mathrm{mg}$ daily after six months' treatment had resulted in polyarthralgia and the brief appearance of a $2.4 \mathrm{~cm}$ diameter subpleural nodule in the lower zone of the right lung. No work was missed then or subsequently and he continues to receive treatment with penicillamine $0.5 \mathrm{~g}$ daily. Two years after the start of treatment there is substantial radiographic evidence of rheumatoid disease in the carpal bones.

\section{Discussion}

Uncertainty about the diagnosis and management of this uncommon and insidious condition may explain why there have been no previous descriptions of penicillamine treatment for rheumatoid lung cavitation. In the 20 years since Lorber ${ }^{6}$ described the treatment of non-cavitated rheumatoid lung disease I have seen six fatalities, attributable to the lack of a recognised remedy. One patient's lung was infected terminally by Mycobacterium xenopi after five years and another by Pseudomonas pyocyaneus after eight years. Two were colonised by mycetoma, one being terminally infected by Staphylococcus aureus after nine years and the other by Pseudomonas aeruginosa after two years. Two others died of destructive enlargement of multiple lung cavities after one year and two years respectively. Such experiences leave a strong impression of the great dangers of prevaricating over these cavities, of which an arthritic patient often is unaware and is therefore undemanding. The hope is that cavity closure through early treatment will remove the possibility of fatal enlargement and infection. For this purpose, penicillamine evidently may be a valuable drug.

Dr R W Barter advocated penicillamine treatment for this patient and permitted access to his notes on the non-pulmonary aspects. Drs G W Bradley, A H Dimond, and W H Seymour allowed illustrative reference to three patients under their care.

\section{References}

1 Ramirez RJ, Campbell GD. Rheumatoid disease of the lung with cavitation. Dis Chest 1966;50:544-7.

2 Locke GB. Rheumatoid lung. Clin Radiol 1963;14:43-53.

3 Jones JS. An account of pleural effusions, pulmonary nodules and cavities attributable to rheumatoid disease. $\mathrm{Br} J$ Dis Chest 1978;72:39-46.

4 Dumas LW, Gregory RL, Ozer FL. Case of rheumatoid lung with cavity formation. Br Med J 1963;1:363.

5 Petrie GR, Bloomfield P, Grant IWB, Crompton GK. Upper lobe fibrosis and cavitation in rheumatoid disease. $\mathrm{Br} J$ Dis Chest 1980;74:263-7.

6 Lorber A. Penicillamine therapy for rheumatoid lung disease; effects on protein sulphydryl groups. Nature 1966;210:1235-7. 